\title{
Compound Danshen Dripping Pill for Treating Nonproliferative Diabetic Retinopathy: A Meta-Analysis of 13 Randomized Controlled Trials
}

\author{
Wenjing Huang, ${ }^{1,2}$ Qi Bao, ${ }^{1,2}$ De Jin, ${ }^{1,2}$ and Fengmei Lian ${ }^{1}$ \\ ${ }^{1}$ Department of Endocrinology, Guang'anmen Hospital, China Academy of Chinese Medical Sciences, Beixiange 5, \\ Xicheng District, Beijing 100053, China \\ ${ }^{2}$ China Academy of Chinese Medical Sciences, Beixiange 5, Xicheng District, Beijing 100700, China
}

Correspondence should be addressed to Fengmei Lian; lfm565@sohu.com

Received 4 December 2016; Revised 12 February 2017; Accepted 23 April 2017; Published 24 August 2017

Academic Editor: Mona Abdel-Tawab

Copyright (c) 2017 Wenjing Huang et al. This is an open access article distributed under the Creative Commons Attribution License, which permits unrestricted use, distribution, and reproduction in any medium, provided the original work is properly cited.

Objective. We assess the clinical effect of compound Danshen dripping pill (CDDP) for treating diabetic retinopathy (DR). Methods. Electronic databases were searched from January 2001 to October 2016 to locate randomized controlled trials (RCTs). Efficacy was measured as main outcome and microaneurysms, hemorrhage, exudate, vision, and fundus fluorescein angiography (FFA) were measured as second outcomes. Methodological quality for each study was evaluated, RevMan 5 software was used to assess treatment effects, and GRADE was used to rate quality of evidence. Results. We located 13 RCTs and methodological quality was evaluated as high risk. Statistics indicated CDDP for treating DR was better than controls and DR risk was reduced 64\% with CDDP (RR: $0.36, P=0.68)$; retinal microaneurysms $(\mathrm{MD}=-4.32 \mathrm{NO}, P<0.00001)$; retinal hemorrhages $(\mathrm{MD}=-0.70 \mathrm{PD}, P=0.03)$; exudate improvements ( $\mathrm{MD}=-0.09 \mathrm{PD}, P=0.79)$; visual changes $(\mathrm{MD}=-0.12$ letter, $P=0.006)$; FFA (RR: $0.40, P=0.003)$. About GRADE, quality of evidence was "low." Conclusion. CDDP may be safe and efficacious for treating or delaying DR and may improve vision or delay vision loss.

\section{Introduction}

Diabetic retinopathy (DR) is a major microvascular complication of diabetes that can lead to retinal detachment and blindness. Annually, 10-12\% of new cases of blindness are attributed to DR and in Holland, as many as $21 \%$ of newly diagnosed blindness is due to DR [1-3]. One-quarter of DR patients develop severe visual impairment, attributed to diabetic macular edema and proliferative diabetic retinopathy (PDR) [4]. Once proliferation begins, it causes irreversible visual impairment. Blindness for diabetics in China is 25 times more frequent than in nondiabetics $[5,6]$ and about 20 million diabetics reside in China now, constituting the second largest diabetes population worldwide [7]. Therefore, preventing DR and reducing diabetic-induced visual impairment are key concerns.

DR treatment includes systemic therapy to control glucose, blood pressure, and serum lipids as well as ocular drugs.
Severe nonproliferative diabetic retinopathy (NPDR) and PDR have been treated with laser therapy, which prevented vision impairment and loss but did not improve visual acuity. Also, laser treatment may reduce visual field. For NPDR, drug intervention can delay progression of DR, improve visual function, and reduce side effects of laser treatment. Thus, the ability to predict progression in early stages of DR and drug intervention are important for reducing the risk of DR. At this time, no effective treatment for DR exists and nothing has been shown to slow or reverse visual impairment.

The pathogenesis of DR is thought to be poor circulation which damages collateral eye vessels [8], so improved circulation is a therapeutic strategy. The herb Salvia miltiorrhiza (Danshen dripping pill, CDDP) was tested in American FDAII clinical trials for safety and efficacy for treating cardiovascular conditions such as myocardial infarction [9]. Also, CDDP is being studied to treat DR [10], although the data quality was poor and safety was not confirmed. Thus, 
we performed a meta-analysis of randomized clinical trials (RCTs) to compare CDDP and placebo or approved therapies to assess any curative effect and safety of this drug.

\section{Methods}

2.1. Data Sources and Search Strategy. We searched the Chinese National Knowledge Infrastructure (CNKI), Chinese Scientific Journal Database (VIP), Chinese Biomedical Literature Database (CBM), WanFang Databases, PubMed, Medline, and Cochrane Library. We used these keywords: ("diabetic retinopathy" OR "diabetic eye diseases") AND ("compound danshen dripping pill" OR "a danshen-containing Chinese herbal medicine") AND ("randomized controlled trial" OR "controlled clinical trial" OR "random" OR "randomly" OR "randomized” OR "control”). We searched all articles published from January 2001 to October 2016.

2.2. Selection of Studies. Randomized controlled trials (RCTs) were selected which included CDDP as the main intervention and this was compared to approved therapy or controls. The primary outcome was efficacy and secondary outcomes were microaneurysms, hemorrhage, exudate, vision, and FFA. Study participants were diagnosed with DR. Medical record reviews, retrospective studies, repeated reports of research studies, and animal experiments were excluded.

2.3. Data Extraction and Quality Assessment. Two authors independently extracted data (W. J. Huang and F. M. Lian) such as author, year of publication and country, sample size, age, sex, intervention (components of intervention), intervention details, dose, treatment duration, changes in microaneurysms, hemorrhage, exudate, visual acuity, and FFA. For incomplete and suspicious data, authors were contacted by e-mail or phoned to obtain the information, but no author offered information. Disagreements over study eligibility were resolved with discussion with a third reviewer (Q. Bao). The Cochrane Handbook for Systematic Review was used to assess study quality [24]. Bias assessment criteria included adequate sequence generation, allocation concealment, blinding of participants and personnel, blinding of outcome assessment, incomplete outcome data addressed, being free of selective reporting, and being free of other biases. We judged each item using three levels ("Yes" means low risk of bias, "No" means high risk of bias, and "Unclear" means other biases); see Table 2 .

2.4. Data Analyses. Revman 5.0 software was used to analyze data, which was provided by the Cochrane Collaboration. The risk ratio (RR) for data was used as pooled statistics, and weighted mean difference (WMD) of measurement data was used as pooled statistics, and 95\% confidence intervals (CI) were calculated [25]. Heterogeneity was assessed by WHAT test and $I^{2}>50 \%$ or $P<0.1$ was used to assess significance, and a random effects model was used to explain possible causes of heterogeneity. If $I^{2}<50 \%$, there was no heterogeneity and a fixed effect model was used [26]. Publication bias was assessed using a funnel plot [27].

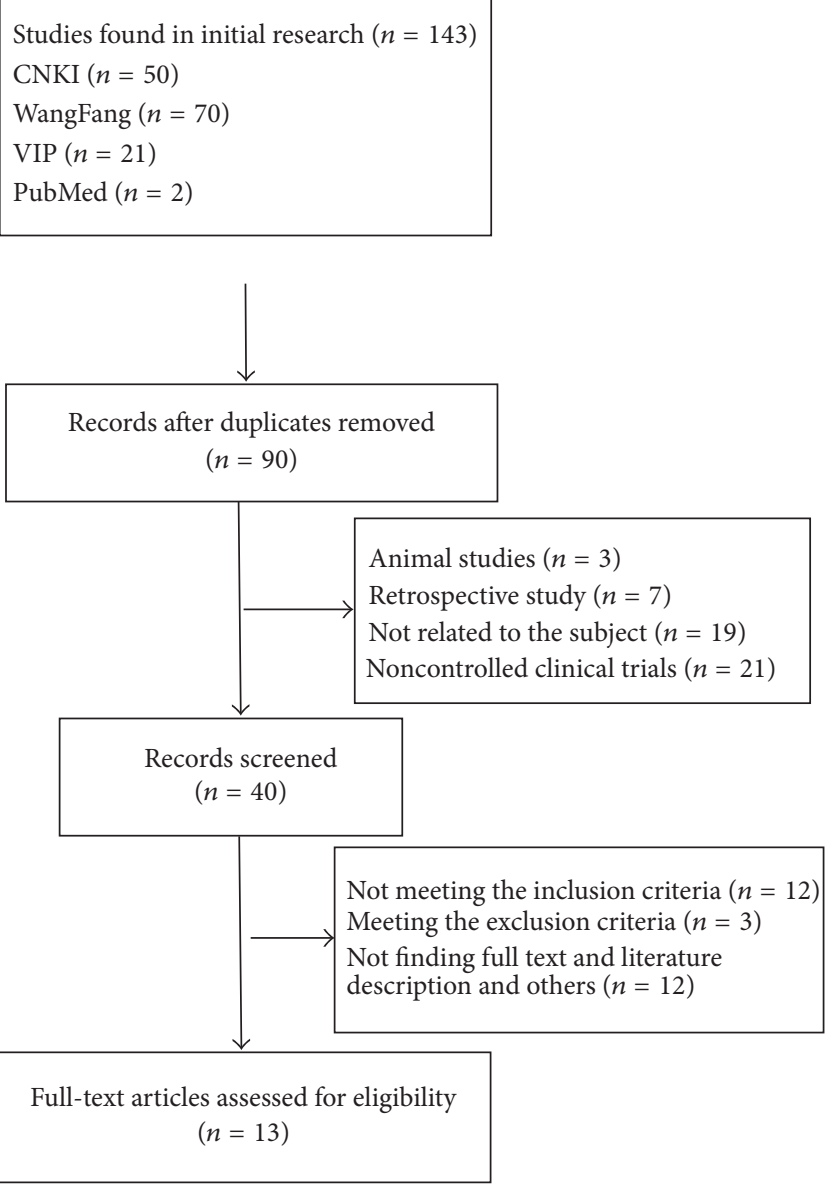

FIGURE 1: Flow chart of studies selection process.

\section{Results}

3.1. Study Characteristics. 143 studies were initially identified; finally, 13 studies [11-22] remained after eliminating duplications, examining titles and abstracts, and reviewing full texts. Figure 1 depicts trial selection and number of studies found. The 13 studies included 874 participants, 477 males and 397 females. Of these, 448 were participants in the intervention group, and 426 were controls. All participants were inpatients/outpatients of the Endocrine Department and they were aged 30 to 80 years. Diagnostic criteria of the 13 studies were based on the accepted and authoritative diagnostic criteria for DR [28-31]. In intervention group, 10 studies [11, 13-15, 17-20, 22, 23] used CDDP alone, and 3 studies [12, 16, 21] used CDDP plus conventional drugs. In control group, 2 studies $[20,21]$ used placebo, 4 studies [11, 13-15] used vitamin B1 and/or LuDing tablets and/or PanShengDing tablets and/or inosine tablets, and 7 studies [16-22] used calcium dobesilate. The follow-up period ranged from 2 to 6 months, and selected studies are summarized in Table 1.

3.2. Quality Assessment. Quality assessments are summarized in Table 2. Only 1 study described methods adequately [23]. The table addresses the remaining study deficits. No 
TABLE 1: Characteristics of included RCTs.

\begin{tabular}{|c|c|c|c|c|c|c|c|}
\hline Trials & $\begin{array}{l}\text { Sample } \\
(N)\end{array}$ & Male : female & Age (years) & Experimental & Control & $\begin{array}{l}\text { Duration } \\
\text { (months) }\end{array}$ & Outcomes measured \\
\hline Qi et al. 2007 [11] & $\begin{array}{c}42 \\
(23 / 19)\end{array}$ & $25: 17$ & $36-72$ & CDDP & $\begin{array}{l}\text { Vitamin B1 + LuDing } \\
\text { tablets }\end{array}$ & 3 & $\begin{array}{l}\text { Visual acuity, } \\
\text { hemorrhage, } \\
\text { microaneurysm }\end{array}$ \\
\hline $\begin{array}{l}\text { He and Zheng } \\
2013[12]\end{array}$ & $\begin{array}{c}84 \\
(42 / 42)\end{array}$ & $48: 36$ & $32-70$ & CDDP & Placebo & 2 & $\begin{array}{l}\text { Visual, exudate, } \\
\text { hemorrhage, } \\
\text { microaneurysm }\end{array}$ \\
\hline Xu 2011 [13] & $\begin{array}{c}80 \\
(40 / 40)\end{array}$ & $39: 41$ & $\begin{array}{l}52.3 \\
54.5\end{array}$ & CDDP & $\begin{array}{l}\text { LuDing tablets + vitamin C } \\
+ \text { PanShengDing tablets }\end{array}$ & 3 & $\begin{array}{l}\text { Efficacy, } \\
\text { microaneurysm }\end{array}$ \\
\hline $\begin{array}{l}\text { Zhon et al. } 2008 \\
{[14]}\end{array}$ & $\begin{array}{c}64 \\
(34 / 30)\end{array}$ & $38: 26$ & $\begin{array}{l}32-72 \\
34-74\end{array}$ & CDDP & LuDing tablets + vitamin C & 3 & $\begin{array}{l}\text { Efficacy, } \\
\text { FFA }\end{array}$ \\
\hline $\begin{array}{l}\text { Liu and Hao } 2011 \\
{[15]}\end{array}$ & $\begin{array}{c}52 \\
(26 / 26)\end{array}$ & $30: 22$ & $39-76$ & CDDP & $\begin{array}{l}\text { LuDing tablets + vitamin C } \\
+ \text { inosine tablets }\end{array}$ & 3 & $\begin{array}{l}\text { Visual acuity, } \\
\text { hemorrhage, } \\
\text { microaneurysm }\end{array}$ \\
\hline $\begin{array}{l}\text { Meng et al. } 2011 \\
{[16]}\end{array}$ & $\begin{array}{c}58 \\
(30 / 28)\end{array}$ & $39: 19$ & $\begin{array}{r}50.60 \pm 8.70 \\
51.20 \pm 7.90\end{array}$ & $\begin{array}{l}\text { CDDP + calcium } \\
\text { dobesilate }\end{array}$ & Calcium dobesilate & 6 & Efficacy \\
\hline $\begin{array}{l}\text { Chen and Zhon } \\
2006 \text { [17] }\end{array}$ & $\begin{array}{c}63 \\
(31 / 32)\end{array}$ & $32: 31$ & $\begin{array}{r}54.60 \pm 10.40 \\
58.12 \pm 9.31\end{array}$ & CDDP & Calcium dobesilate & 3 & $\begin{array}{l}\text { Efficacy, } \\
\text { visual acuity }\end{array}$ \\
\hline Zhou 2008 [18] & $\begin{array}{c}46 \\
(28 / 18)\end{array}$ & $23: 23$ & $\begin{array}{r}50.40 \pm 8.70 \\
50.50 \pm 9.36\end{array}$ & CDDP & Calcium dobesilate & 6 & Efficacy \\
\hline $\begin{array}{l}\text { Wang et al. } 2016 \\
\text { [19] }\end{array}$ & $\begin{array}{c}90 \\
(45 / 45)\end{array}$ & $47: 43$ & $\begin{array}{l}47-77 \\
48-76\end{array}$ & CDDP & Calcium dobesilate & 2 & $\begin{array}{c}\text { Efficacy, } \\
\text { visual acuity, FFA }\end{array}$ \\
\hline Jin et al. 2009 [20] & $\begin{array}{c}58 \\
(30 / 28)\end{array}$ & $31: 27$ & $\begin{array}{r}62.78 \pm 7.69 \\
61.11 \pm 7.27\end{array}$ & CDDP & Calcium dobesilate & 3 & $\begin{array}{l}\text { Visual acuity, } \\
\text { hemorrhage, } \\
\text { microaneurysm }\end{array}$ \\
\hline Shi 2010 [21] & $\begin{array}{c}68 \\
(35 / 33)\end{array}$ & $36: 32$ & $38-76$ & $\begin{array}{l}\text { CDDP + calcium } \\
\text { dobesilate }\end{array}$ & Calcium dobesilate & 3 & Efficacy \\
\hline $\begin{array}{l}\text { Luo et al. } 2015 \\
\text { [22] }\end{array}$ & $\begin{array}{c}57 \\
(28 / 29)\end{array}$ & $37: 20$ & $\begin{array}{r}59.54 \pm 7.46 \\
57.8 \pm 10.03\end{array}$ & CDDP & Calcium dobesilate & 3 & $\begin{array}{l}\text { Visual acuity, } \\
\text { hemorrhage, } \\
\text { microaneurysm }\end{array}$ \\
\hline $\begin{array}{l}\text { Lian et al. } 2015 \\
{[23]}\end{array}$ & $\begin{array}{c}112 \\
(56 / 56)\end{array}$ & $52: 60$ & $\begin{array}{c}58.97 \pm 7.6 \\
58.97 \pm 8.1\end{array}$ & CDDP & Placebo & 6 & $\begin{array}{c}\text { Exudate, } \\
\text { hemorrhage, FFA, } \\
\text { microaneurysm }\end{array}$ \\
\hline
\end{tabular}

study clearly described method of allocation concealment and blinding procedures. All studies showed the baseline data of the two groups were "comparable," and quit and lost to follow-up cases and adverse events were not recorded. The methodological quality was assessed to be of high risk.

\subsection{Effect of the Interventions}

3.3.1. Efficacy. According to Guiding Principles of Clinical Research on Chinese Medicine Traditional and New Drugs, efficacy was assessed based on fundal improvements measured with ophthalmoscopy, fundus fluorescein angiography (FFA) to assess microaneurysms, hemorrhage and exudate areas, and improved vision using a visual chart [28]. Efficacy was evaluated being significantly effective, effective, and ineffective. Total efficacy was evaluated based on significantly effective and effective data, and this was a chief overall outcome. Seven studies were examined $[13,16-19,21,23]$ and their data were homogenous and DR risk was reduced $64 \%$ by CDDP (RR: $0.36, \mathrm{Chi}^{2}=4.01, P=0.68, I^{2}=0 \%, 95 \%$ CI $[0.28$ to 0.46$]$, and $P<0.00001)$. Thus, a fixed effects model was used for statistical analysis and data showed that treatment groups fared significantly better than controls. To compare curative effects of treatment and controls, subgroup was used. Two studies $[16,21]$ used CDDP plus conventional drugs for treatment, and five studies [13, 17-19, 23] only used CDDP for treatment. Two kinds of studies suggested that treatment was better than controls ( $N=126, \mathrm{RR}: 0.27,95 \% \mathrm{CI}$ [ 0.13 to 0.59 ], $Z=3.33$, and $P=0.0009$ and $N=391$, RR: $0.38,95 \%$ CI $[0.29$ to 0.49 ], $Z=7.33$, and $P<0.00001)$ and these data appear in Figure 2.

3.3.2. Microaneurysms. Five studies $[11,12,15,20,22]$ reported participants who had more microaneurysms $\left(\mathrm{Chi}^{2}=2.50\right.$, $P=0.65$, and $\left.I^{2}=0 \%\right)$. Thus, fixed effects model was used for statistical analysis. Microaneurysms were significantly improved in the treatment group compared with controls $(N=293, Z=7.76, \mathrm{MD}=-4.32,95 \% \mathrm{CI}[-5.41$ to -3.23$]$, and $P<0.00001)$; see Figure 3.

3.3.3. Hemorrhages. Six studies $[11,12,15,20,22,23]$ provided data for improvements of retinal hemorrhages. Significant heterogeneity was found among these six studies $\left(\mathrm{Chi}^{2}=\right.$ 
TABLE 2: Quality assessment of enrolled RCTs.

\begin{tabular}{|c|c|c|c|c|c|c|c|c|}
\hline Studies & $\begin{array}{l}\text { Adequate } \\
\text { sequence } \\
\text { generation }\end{array}$ & $\begin{array}{c}\text { Allocation } \\
\text { concealment }\end{array}$ & $\begin{array}{l}\text { Blinding of } \\
\text { participants } \\
\text { and } \\
\text { personnel }\end{array}$ & $\begin{array}{l}\text { Blinding of } \\
\text { outcome } \\
\text { assessment }\end{array}$ & $\begin{array}{c}\text { Incomplete } \\
\text { outcome data } \\
\text { addressed }\end{array}$ & $\begin{array}{c}\text { Free of } \\
\text { selective } \\
\text { reporting }\end{array}$ & $\begin{array}{c}\text { Free of other } \\
\text { biases }\end{array}$ & Risk of bias \\
\hline $\begin{array}{l}\text { Qi et al. } 2007 \\
\text { [11] }\end{array}$ & Unclear & Unclear & No & Unclear & Yes & No & Unclear & High \\
\hline $\begin{array}{l}\text { He and } \\
\text { Zheng } 2013 \\
{[12]}\end{array}$ & Unclear & Unclear & Unclear & Unclear & Yes & No & Unclear & High \\
\hline Xu 2011 [13] & Unclear & Unclear & Unclear & Unclear & Yes & No & Unclear & High \\
\hline $\begin{array}{l}\text { Zhon et al. } \\
2008 \text { [14] }\end{array}$ & Unclear & Unclear & Unclear & Unclear & No & Yes & Unclear & High \\
\hline $\begin{array}{l}\text { Liu and Hao } \\
2011[15]\end{array}$ & Unclear & Unclear & Unclear & Unclear & Yes & No & Unclear & High \\
\hline $\begin{array}{l}\text { Meng et al. } \\
2011 \text { [16] }\end{array}$ & Unclear & Unclear & Unclear & Unclear & No & Yes & Unclear & High \\
\hline $\begin{array}{l}\text { Chen and } \\
\text { Zhon } 2006 \\
{[17]}\end{array}$ & Unclear & Unclear & Unclear & Unclear & No & Yes & Unclear & High \\
\hline $\begin{array}{l}\text { Zhou } 2008 \\
{[18]}\end{array}$ & Unclear & Unclear & Unclear & Unclear & Yes & No & Unclear & High \\
\hline $\begin{array}{l}\text { Wang et al. } \\
2016 \text { [19] }\end{array}$ & Unclear & Unclear & Unclear & Unclear & Yes & No & Unclear & High \\
\hline $\begin{array}{l}\text { Jin et al. } 2009 \\
\text { [20] }\end{array}$ & Unclear & Unclear & Unclear & Unclear & Yes & No & Unclear & High \\
\hline Shi 2010 [21] & Unclear & Unclear & No & Unclear & Yes & No & Unclear & High \\
\hline $\begin{array}{l}\text { Luo et al. } \\
2015 \text { [22] }\end{array}$ & Unclear & Unclear & Unclear & Unclear & Yes & No & Unclear & High \\
\hline $\begin{array}{l}\text { Lian et al. } \\
2015 \text { [23] }\end{array}$ & Yes & Yes & Yes & Yes & Yes & Yes & Yes & Low \\
\hline
\end{tabular}

65.52, $P<0.00001$, and $\left.I^{2}=92 \%\right)$. Using a random effects model, we confirmed a significant difference between treatments and controls $(N=405, Z=2.14, \mathrm{MD}=-0.70$, $95 \%$ CI $[-0.76$ to -0.03$]$, and $P=0.03)$; see Figure 4 .

3.3.4. Exudate. Two trials $[12,23]$ provided data for exudate, and they did not show homogeneity $\left(\mathrm{Chi}^{2}=9.69, P=0.002\right.$, and $\left.I^{2}=90 \%\right)$. A random effects model indicated that there were no significant differences between treatment groups and controls so there may have been differences in intervention measures, observation methods, or periods of intervention $(N=196, Z=0.27, \mathrm{MD}=-0.09,95 \% \mathrm{CI}[-0.71$ to 0.54$]$, $Z=0.27$, and $P=0.79$ ); see Figure 5 .

3.3.5. Visual. Five studies $[11,15,17,20,22]$ reported data for visual acuity and significant heterogeneity was found $\left(\mathrm{Chi}^{2}\right.$ $=14.35, P=0.006$, and $\left.I^{2}=72 \%\right)$. A random effects model indicated that there were significant differences between treatment groups and controls $(N=272, Z=2.77, \mathrm{MD}=$ $-0.12,95 \%$ CI [ -0.21 to -0.07$], Z=2.77$, and $P=0.006$ ); see Figure 6.

3.3.6. Fundus Fluorescein Angiography (FFA). Three studies $[18,19,23]$ provided data for fundal improvements and they did not show homogeneity $\left(\mathrm{Chi}^{2}=5.99, P=0.05\right.$, and $I^{2}$ $=67 \%)$. A random effects model indicated that treatment groups improved more than controls $(N=266, Z=3.02$, RR: $0.40,95 \%$ CI [ 0.22 to 0.73 ], and $P=0.003$ ); see Figure 7.

3.4. Publication Bias. An "inverted funnel" pattern analysis was used to confirm publication bias and the asymmetrical figure indicated potential publication bias that might influence results (Figure 8). Although we conducted comprehensive search to avoid bias, some negative results may not have been published. Study quality was not homogeneous, and most studies did not indicate randomization approaches. Other deficits may have compromised bias. Even so, included studies had definite diagnostic criteria, and baselines of treatment groups and controls were comparable. Thus, we conclude that CDDP improve fundal lesions of DR participants.

3.5. Result of GRADE. GRADE provides a clear and comprehensive methodology for rating the confidence in estimates (quality of evidence). It was used to evaluate effects of CDDP on DR and we confirmed a low quality of evidence. Better high-quality RCTs are needed to confirm the effect of CDDP, Table 3. 


\begin{tabular}{|c|c|c|c|c|c|c|c|c|c|c|c|}
\hline \multirow{2}{*}{ Study or subgroup } & \multicolumn{2}{|c|}{ Treatment } & \multicolumn{2}{|c|}{ Control } & \multirow{2}{*}{ Weight } & \multirow{2}{*}{$\begin{array}{c}\text { Risk ratio } \\
\text { M-H, fixed, 95\% CI }\end{array}$} & \multirow{2}{*}{\multicolumn{5}{|c|}{$\begin{array}{c}\text { Risk ratio } \\
\text { M-H, fixed, 95\% CI }\end{array}$}} \\
\hline & Events & Total & Events & Total & & & & & & & \\
\hline \multicolumn{12}{|c|}{ 1.1.1 CDDP $+C$ versus $C$} \\
\hline Shi 2010 & 3 & 35 & 11 & 33 & $8.1 \%$ & $0.26[0.08,0.84]$ & & & & & \\
\hline Meng et al. 2011 & 4 & 30 & 13 & 28 & $9.6 \%$ & $0.29[0.11,0.78]$ & & & & & \\
\hline Subtotal $(95 \% \mathrm{CI})$ & & 65 & & 61 & $17.8 \%$ & $0.27[0.13,0.59]$ & & & & & \\
\hline Total events & 7 & & 24 & & & & & & & & \\
\hline \multicolumn{12}{|c|}{ Heterogeneity: $\chi^{2}=0.02, d f=1(P=0.89) ; I^{2}=0 \%$} \\
\hline \multicolumn{12}{|c|}{ Test for overall effect: $Z=3.33(P=0.0009)$} \\
\hline \multicolumn{12}{|l|}{ 1.1.2 CDDP versus $C$} \\
\hline Zhou 2008 & 4 & 28 & 8 & 18 & $7.0 \%$ & $0.32[0.11,0.91]$ & & & & & \\
\hline Hua 2011 & 13 & 40 & 35 & 40 & $25.1 \%$ & $0.37[0.23,0.59]$ & & & & & \\
\hline Wang et al. 2016 & 2 & 45 & 11 & 45 & $7.9 \%$ & $0.18[0.04,0.77]$ & & & & & \\
\hline Lian et al. 2015 & 23 & 56 & 50 & 56 & $35.9 \%$ & $0.46[0.33,0.64]$ & & & & & \\
\hline Chen and Zhon 2006 & 2 & 31 & 9 & 32 & $6.4 \%$ & $0.23[0.05,0.98]$ & & & & & \\
\hline Subtotal $(95 \% \mathrm{CI})$ & & 200 & & 191 & $82.2 \%$ & $0.38[0.29,0.49]$ & & & & & \\
\hline Total events & 44 & & 113 & & & & & & & & \\
\hline \multicolumn{12}{|c|}{ Heterogeneity: $\chi^{2}=2.95, d f=4(P=0.57) ; I^{2}=0 \%$} \\
\hline \multicolumn{12}{|c|}{ Test for overall effect: $Z=7.33(P<0.00001)$} \\
\hline Total $(95 \%$ CI $)$ & & 265 & & 252 & $100.0 \%$ & $0.36[0.28,0.46]$ & & & & & \\
\hline Total events & 51 & & 137 & & & & & & & & \\
\hline \multicolumn{12}{|c|}{ Heterogeneity: $\chi^{2}=4.01, d f=6(P=0.68) ; I^{2}=0 \%$} \\
\hline \multicolumn{7}{|c|}{ Test for overall effect: $Z=8.05(P<0.00001)$} & 0.01 & 0.1 & 1 & 10 & 100 \\
\hline \multicolumn{7}{|c|}{ Test for subgroup differences: not applicable } & & s tre & & urs ce & \\
\hline
\end{tabular}

Figure 2: Comparison of efficacy of CDDP.

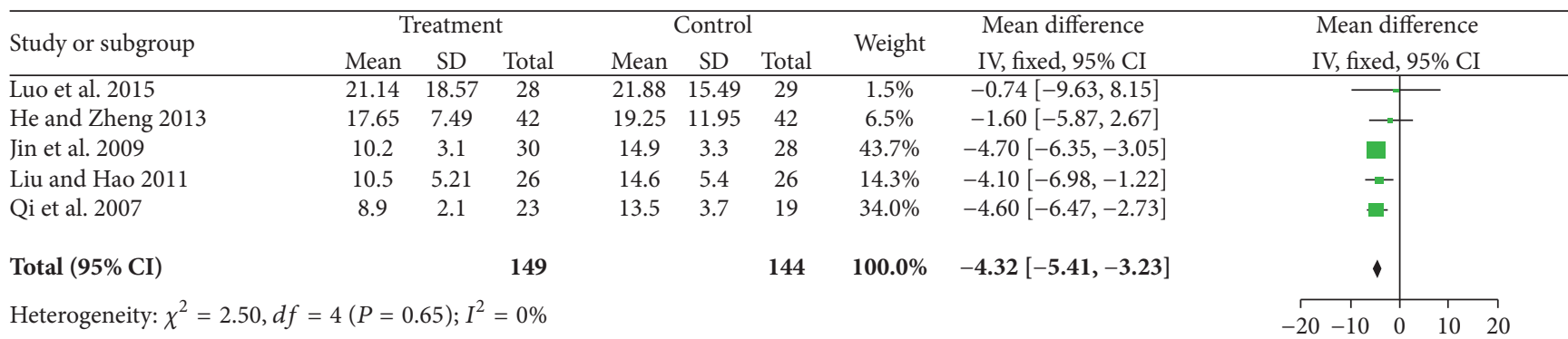

Test for overall effect: $Z=7.76(P<0.00001)$

Favours treatment Favours control

FIGURE 3: A comparison of the effectiveness of CDDP on retinal microaneurysms improvement.

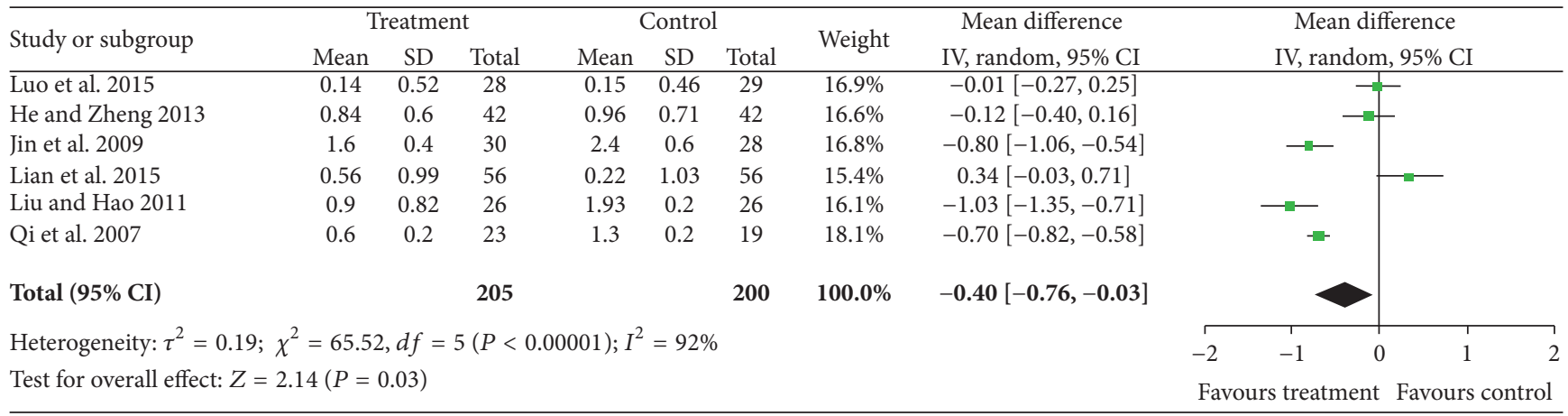

FIGURE 4: A comparison of the effectiveness of CDDP on hemorrhage improvement. 


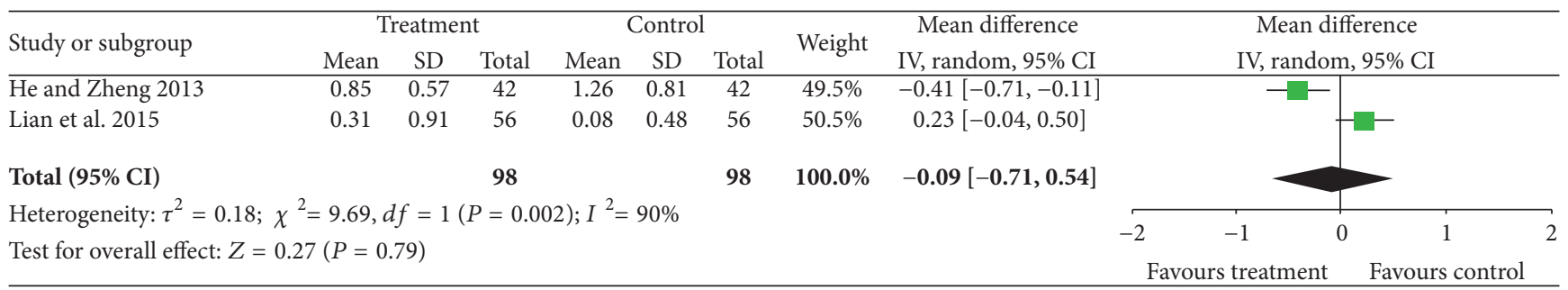

FIGURE 5: A comparison of the effectiveness of CDDP on exudate improvement.

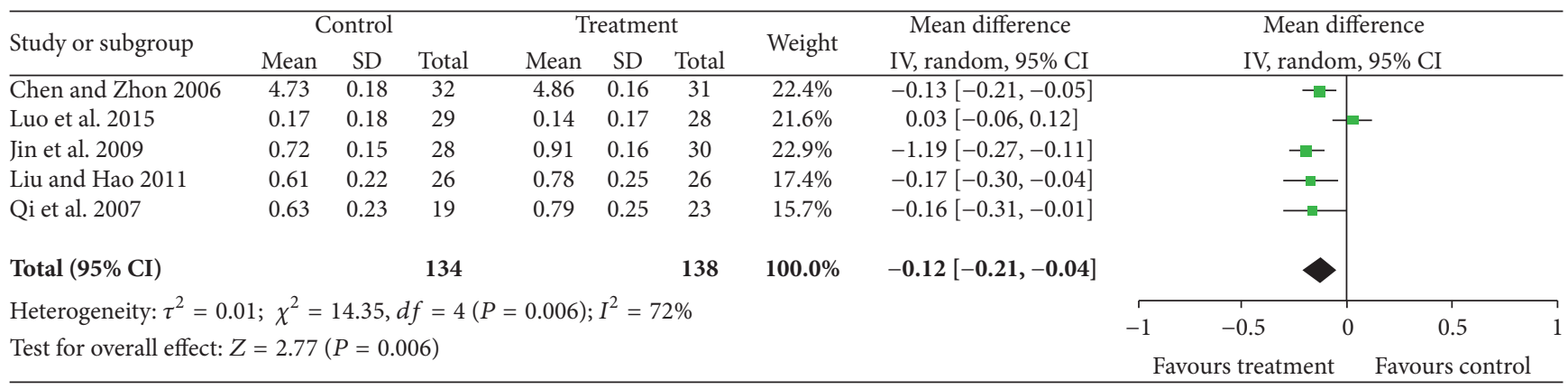

FIGURE 6: CDDP efficacy for vision improvement.

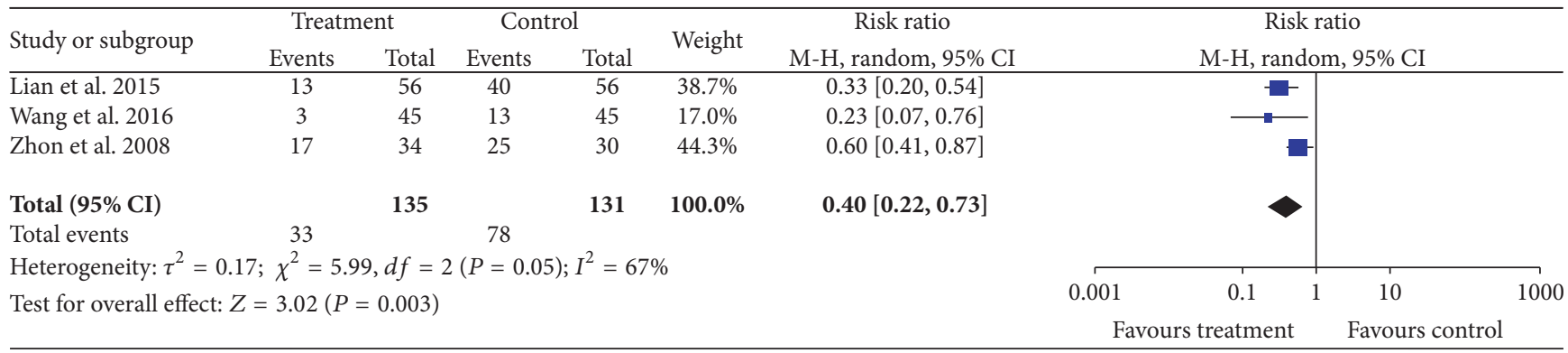

FIGURE 7: CDDP efficacy for FFA.

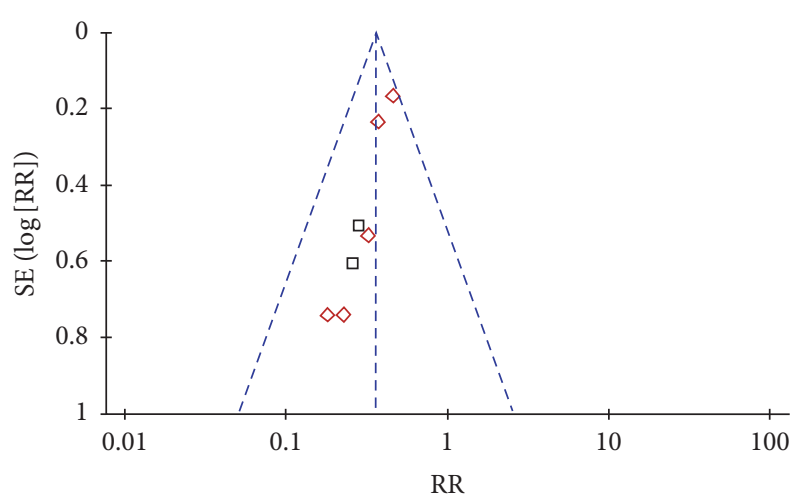

FIGURE 8: Funnel plot of publication bias.

3.6. Adverse Events. No adverse events were recorded in any study, suggesting that CDDP may be safe.

\section{Discussion}

Our data suggest that 270-540 mg CDDP may be used to treat $\mathrm{DR}$ as improvements in various indicators were noted. Of the 13 studies reviewed, the curative effect of CDDP for DR was shown to be superior to controls and this was significantly different for vision improvements. This suggests that CDDP may delay vision loss and retard the progression of $\mathrm{DR}$. The advantages of studies included definite diagnostic criteria and "comparability" for baseline data. But studies were of high risk methodological quality and samples were small. There was no multicenter trial or large samples for collaborative research. Only one study described the randomization method. Many participants were lost and not followed-up! There are five proposals: first, record in detail data of participants who were lost to follow-up or quit midway; second, record long followup and record important clinical outcomes after treatment, such as progression of retinopathy to PDR or sustained visual loss; third, methodological quality of clinical studies 


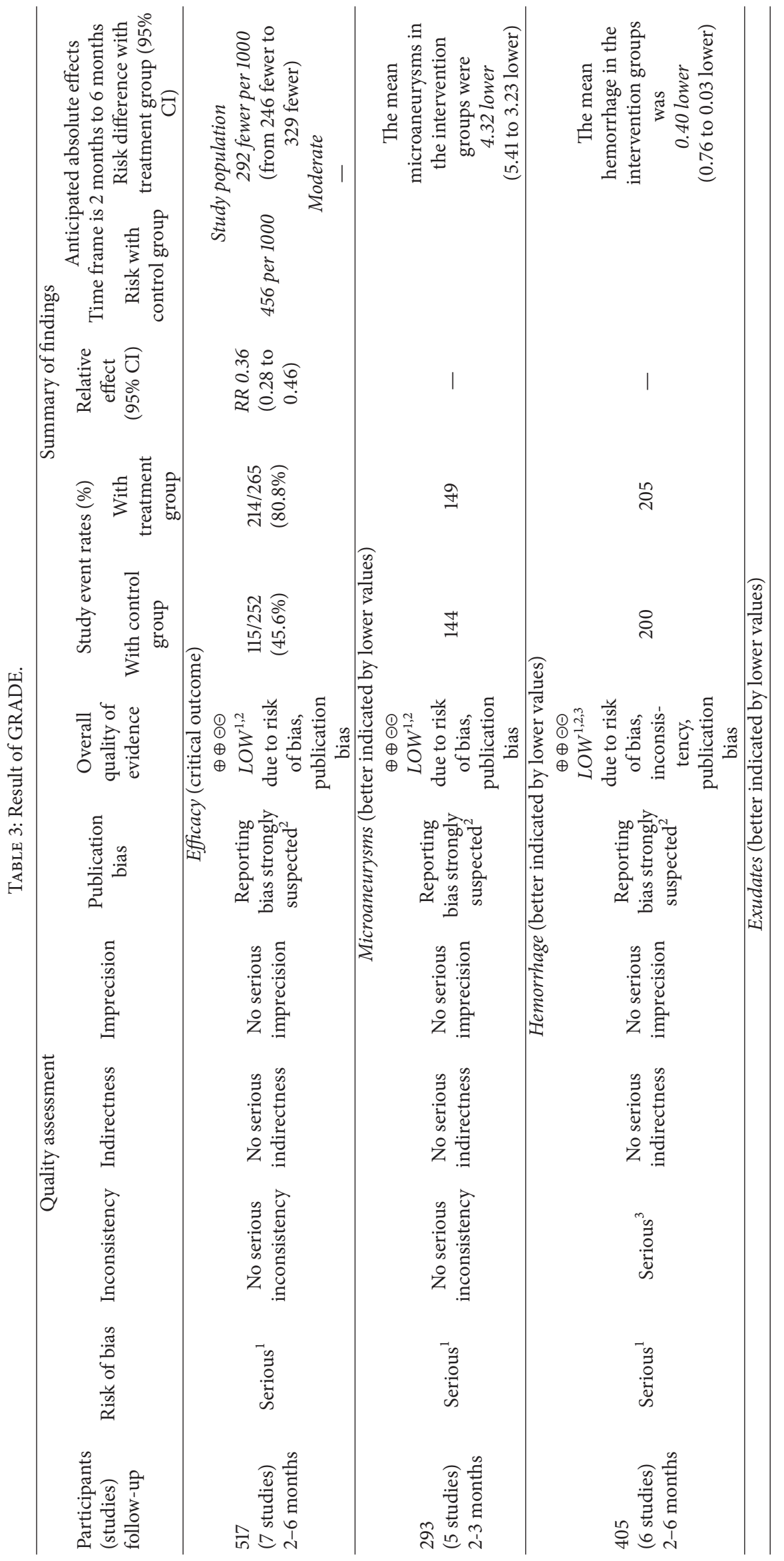




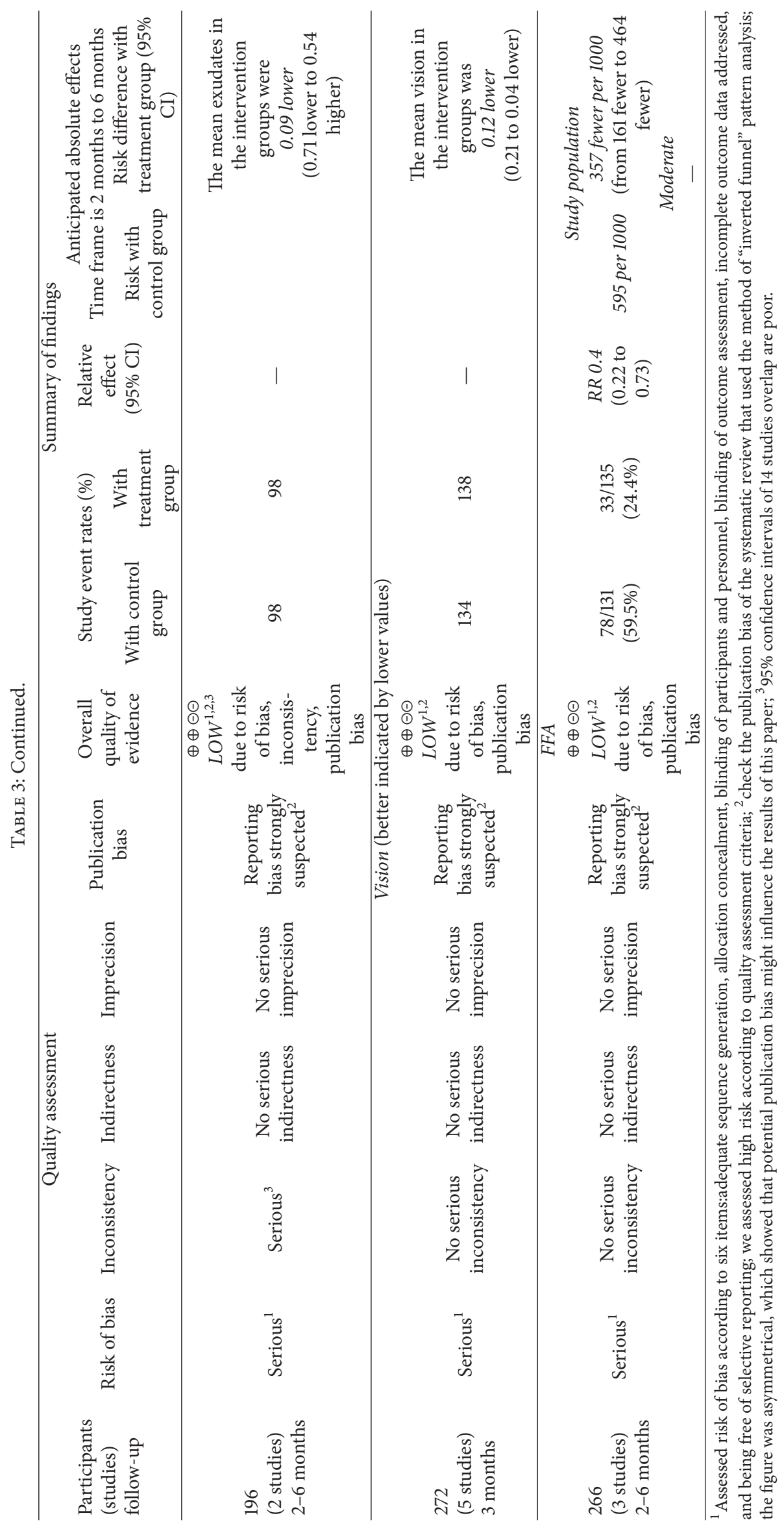


should use allocation concealment and complete outcome data should be addressed to prevent bias [32]; fourth, use the internationally accepted, uniform, and objective indicators of curative effect $[33,34]$; fifth, for search, the negative result of studies must be included.

CDDP is compounded from extracts of S. miltiorrhiza, notoginseng (Panax notoginseng) and borneol. These three traditional Chinese medicines are widely used and have a long history of treatment in China. S. Miltiorrhiza and Panax notoginseng are used to treat cardiovascular conditions [35, 36]. S. miltiorrhiza contains a water soluble tanshinol which allegedly can decrease coagulation, increase fibrinolytic activity, inhibit thrombosis, platelet synthesis, and prostacyclin release, as well as block hydroxyl radical production, prevent lipid peroxidation, and scavenge free radicals [37].

Mechanisms underlying CDDP may include free radical scavenging as S. miltiorrhiza ketone IIA can inhibit lipid peroxidation and reduce free radicals to protect endothelial diastolic function and vision and visual acuity was reportedly improved after treatment with CDDP [38, 39]. Improved microvascular structure was noted after CDDP treatment. The average thickness of micrangium decreased and diameters widened after CDDP for intake 3 months [18]. CDDP may improve microcirculation near the retina, opening capillaries, and relieving tissue ischemia and hypoxia and this can reduce DR symptoms or delay disease progression [40]. Endothelial dysfunction is prominent in hypercholesterolemic patients and it may contribute to DR by endothelial dysfunction [41]. CDDP may improve lipid metabolism. Hyperlipidemia damages the vascular wall and causes endothelial dysfunction, changing cell membrane structure and leading to microthrombi and ultimately causing DR. CDDP may then delay progression of DR by reducing blood lipids and improving blood flow $[42,43]$. CDDP uses multiple sites, multiple pathways, and multitargets. It is characterized by convenient taking, rapid onset of action, and no obvious toxicity or adverse reactions.

\section{Conclusion}

From this meta-analysis, we find that CDDP can be safe and efficacious retarding the progression of DR and delaying vision loss; thus it may be considered as an alternative way to treat $\mathrm{DR}$. But the methodological quality was assessed to be of high risk and GRADE quality of evidence was "low." Thereby, large-sample, high-quality randomized controlled clinical trials are warranted in the future.

\section{Conflicts of Interest}

There are no conflicts of interest.

\section{Acknowledgments}

This paper is supported by the 2015 Traditional Chinese Medicine Scientific Research (no. 201507001-11).

\section{References}

[1] F. Kyari, A. Tafida, S. Sivasubramaniam et al., "Prevalence and risk factors for diabetes and diabetic retinopathy: Results from the Nigeria national blindness and visual impairment survey," BMC Public Health, vol. 14, no. 1, article no. 1299, 2014.

[2] L. P. Aiello and DCCT/EDIC Research Group, "Diabetic retinopathy and other ocular findings in the diabetes control and complications trial/epidemiology of diabetes interventions and complications study," Diabetes Care, vol. 37, no. 1, pp. 17-23, 2014.

[3] D. M. Nathan, M. Bayless, P. Cleary et al., "Diabetes control and complications trial/epidemiology of diabetes interventions and complications study at 30 years: Advances and contributions," Diabetes, vol. 62, no. 12, pp. 3976-3986, 2013.

[4] R. Klein, B. E. K. Klein, and S. E. Moss, "Visual impairment in diabetes," Ophthalmology, vol. 91, no. 1, pp. 1-9, 1984.

[5] F. H. Wang, Y. B. Liang, F. Zhang et al., "Prevalence of diabetic retinopathy in rural China: the handan eye study," Ophthalmology, vol. 116, no. 3, pp. 461-467, 2009.

[6] R. Varma, G. Wen, X. Jiang et al., "Prevalence of diabetic retinopathy in adult Chinese American individuals: The Chinese American eye study," JAMA Ophthalmology, vol. 134, no. 5, pp. 563-569, 2016.

[7] S. Wild, G. Roglic, A. Green, R. Sicree, and H. King, "Global prevalence of diabetes: estimates for the year 2000 and projections for 2030," Diabetes Care, vol. 27, no. 5, pp. 1047-1053, 2004.

[8] J. G. Duan and M. Jin, "Standard of TCM diagnosis and treatment of diabetic retinal lesions," World Journal of Integrated Traditional and Western Medicine, vol. 6, pp. 632-637, 2011.

[9] J. Luo, H. Xu, and K. Chen, "Systematic review of compound danshen dropping pill: a chinese patent medicine for acute myocardial infarction," Evidence-Based Complementary and Alternative Medicine, vol. 2013, Article ID 808076, 15 pages, 2013.

[10] Y. Chu, L. Zhang, X.-Y. Wang, J.-H. Guo, Z.-X. Guo, and X.-H. $\mathrm{Ma}$, "The effect of compound danshen dripping pills, a Chinese herb medicine, on the pharmacokinetics and pharmacodynamics of warfarin in rats," Journal of Ethnopharmacology, vol. 137, no. 3, pp. 1457-1461, 2011.

[11] C.-X. Qi, X.-H. Tan, Q.-G. Li, and X.-L. Wang, "Clinical study of diabetic retinopathy treated by compound danshen dripping pills treating diabetic retinopathy," Journal of Chinese Medicinal Materials, vol. 30, no. 3, pp. 375-377, 2007.

[12] G. He and D. Zheng, "Clinical observation of compound danshen dripping pills treating of non proliferative diabetic retinopathy," Journal of Lanzhou University, vol. 04, pp. 76-78, 2013.

[13] H. Xu, "Observation of therapeutic effect of compound danshen dripping pills treating diabetic retinopathy," Journal of China Practical Medicine, vol. 35, pp. 142-143, 2011.

[14] R. Zhon, Y. Xie, and X. Tan, "Effect of compound danshen dripping pills on the concentration of endothelin in diabetic retinopathy," in Modern Magazine of Combines Traditional Chinese Medicine with Western Medicine, vol. 25, pp. 3955-3956, 25, 2008.

[15] M. Liu and J. Hao, "Clinical observation of compound danshen dripping pills treating of early diabetic retinopathy," in Journal of Chinese and Foreign Medical Treatment, vol. 10, p. 11, 9, 2011.

[16] X. Meng, S. Shu, and Y. Duan, "Clinical observation of compound danshen dripping pills combined with calciumdobesilate treating diabetic retinopathy," Journal of Medical Forum, vol. 13, pp. 137-138, 2011. 
[17] Y. Chen and Y. Zhon, "Clinical study of compound danshen dripping Pills treating simple diabetic retinopathy," Journal of Chinese Community Doctor, vol. 23, 75 pages, 2006.

[18] L. Zhou, "Clinical observation of compound danshen dripping pills treating diabetic retinopathy," Journal of Chinese Medicine Guides, pp. 1-77, 2008.

[19] H. Wang, D. Tian, and X. Han, "Observation of the effect of compound danshen dripping pills treating non proliferative diabetic retinopathy," Journal of Clinical Rational Drug Use, vol. 23, pp. 49-50, 2016.

[20] M. Jin, H. Deng, and W. Yuan, "Clinical observation of compound danshen dripping pills treating early diabetic retinopathy," Journal of Chinese Community Doctor, vol. 16, pp. 32-33, 2009.

[21] H. Shi, "Experience in the treatment of diabetic retinopathy," Journal of Medical Forum, vol. 04, pp. 100-102, 2010.

[22] D. Luo, Y. Qin, W. Yuan, and etal., "Compound danshen dripping pill for treating early diabetic retinopathy: a randomized, double-dummy, double-blind study," Evidence-Based Complementary and Alternative Medicine, vol. 2015, Article ID 539185, 7 pages, 2015.

[23] F. Lian, L. Wua, and J. Tiana, "The effectiveness and safety of a danshen-containing Chinese herbal medicine for diabetic retinopathy: a randomized, double-blind,placebo-controlled multicenter clinical trial," Journal of Ethnopharmacology, vol. 164, pp. 71-77, 2015.

[24] J. P. T. Higgins and S. Green, Corchrane Reviewer'Handbook 5.1.0, ReviewManager (RevMan) [Computerprogram]. Version 5.1.0.

[25] C. Changsheng, "Yongyong Xu. Fourteenth speak: how to carry out Meta analysis," Chinese Journal of Preventive Medicine, vol. 37, no. 2, pp. 138-140, 2003.

[26] N. Zongzan, Medlical statistics, Higher Education Press, 2003, 241-251.

[27] D. Kang, Q. Hong, L. Guanjian, and etal., "Identification and processing of publication bias in Meta analysis," Chinese Journal of Evidence-based Medicine, vol. 3, no. 1, pp. 45-49, 2003.

[28] Y. Zheng, Guiding principles of clinical research on Chinese medicine traditional and new drugs, Nanjing University Press, Nanjing, China, 2002.

[29] Ophthalmic branch of the Chinese Medical Association. Criteria for diabetic retinopathy. Journal of Ocular fundus disease, $1985,1: 42$.

[30] L. Jiaqi Fengming, Practical Ophthalmology. People's Medical Publishing House, Version 2, 2003: 481.

[31] Z. Huifen, C. Jiamin, and W. Ruiping, Practical Diabetes. Beijing: People's Medical Publishing House, Version 2, 2001: 164-171.

[32] K. F. Schulz and D. A. Grimes, "Generation of allocation sequences in randomised trials: chance, not choice," The Lancet, vol. 359, no. 9305, pp. 515-519, 2002.

[33] P. Glasziou, L. Chalmers, M. Rawlins, and P. McCulloch, "When are randomised trials unnecessary? Picking signal from noise," British Medical Journal, vol. 334, pp. 349-351, 2007.

[34] G. H. Guyatt, A. D. Oxman, R. Kunz, G. E. Vist, Y. Falck-Ytter, and H. J. Schünemann, "What is "quality of evidence" and why is it important to clinicians?" British Medical Journal, vol. 336, no. 7651, pp. 995-998, 2008.

[35] C. H. Park, D. H. Kim, and M. H. Park, "Chinese prescription Kangenkaryu and Salviae miltiorrhizae radix improve agerelated oxidative stress and inflammatory response through the
PI3K/Akt or MAPK pathways," American Journal of Chinese Medicine, vol. 42, no. 4, pp. 987-1005, 2014.

[36] H. Xu, D. Wang, C. Peng et al., "Rabbit sera containing compound danshen dripping pill attenuate leukocytes adhesion to TNF-alpha-activated human umbilical vein endothelial cells by suppressing endothelial ICAM-1 and VCAM-1 expression through NF-KB signaling pathway," Journal of Cardiovascular Pharmacology, vol. 63, no. 4, pp. 323-332, 2014.

[37] S. Jianbo, J. Lian, Y. Yuxian, and etal., "Clinical application and mechanism of compound danshen dripping pill," Modern magazine of combines traditional Chinese medicine with western medicine, vol. 11, no. 11, 2002, 1087.

[38] Y. Sun and D. Yan, "Drug treatment of diabetic retinopathy," Journal of Chinese medicine guides, vol. 4, no. 32, pp. 6-8, 2007.

[39] Q. P. Zhao, "Study on the establishment and compound danshen dripping pills of blood stasis in rat model of acute blood stasis," Journal of Ningxia Medical University, vol. 33, pp. 849-852, 2011.

[40] M. Jie, "Discuss the mechanism of compound danshen dropping pill treatment of diabetic retinopathy," Journal of Chinese Medicine Information, vol. 3, pp. 81-82, 2007.

[41] R. Benarous, M. B. Sasongko, S. Qureshi et al., "Differential association of serum lipids with diabetic retinopathy and diabetic macular edema," Investigative Ophthalmology and Visual Science, vol. 52, no. 10, pp. 7464-7469, 2011.

[42] F. L. Ferris, E. Y. Chew, and B. J. Hoogwerf, "Serum lipids and diabetic retinopathy," Journal of Diabetes Care, vol. 19, no. 11, pp. 1291-1293, 1996.

[43] Z. Qipeng, "Study on the establishment and compound danshen dripping pills of blood stasis in rat model of acute blood stasis," Journal of Ningxia Medical University, vol. 9, pp. 849-852, 2011. 


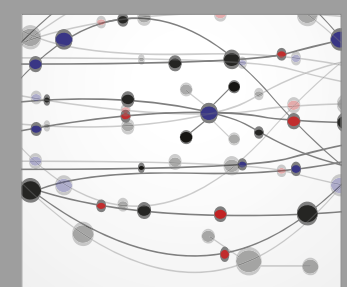

The Scientific World Journal
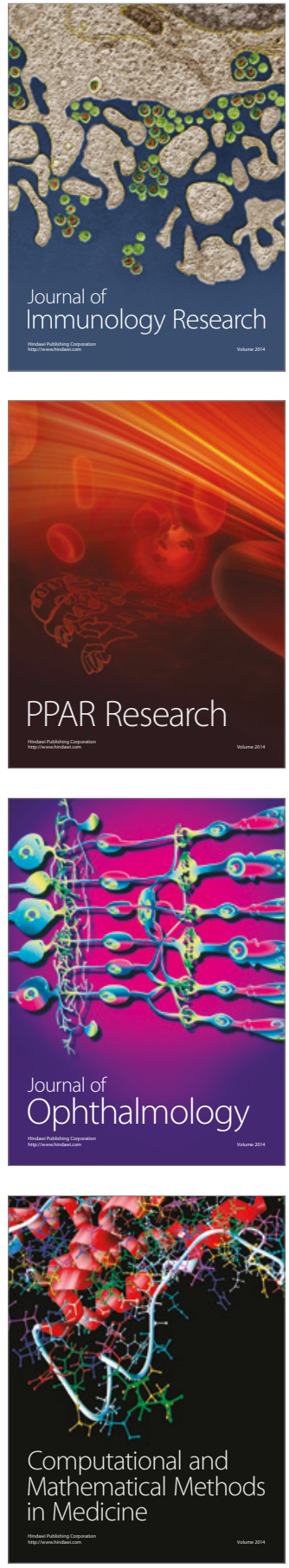

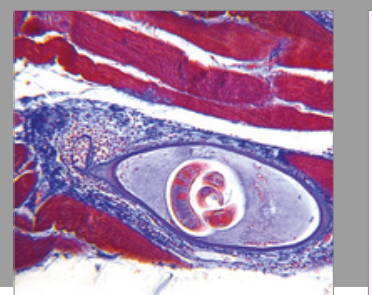

Gastroenterology Research and Practice
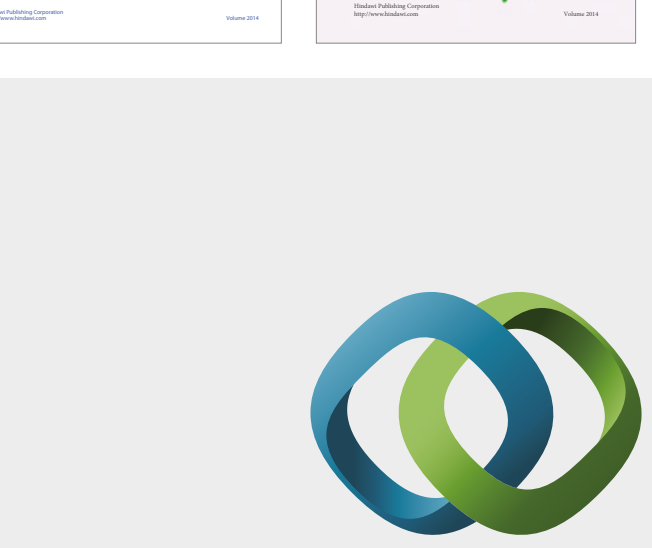

\section{Hindawi}

Submit your manuscripts at

https://www.hindawi.com
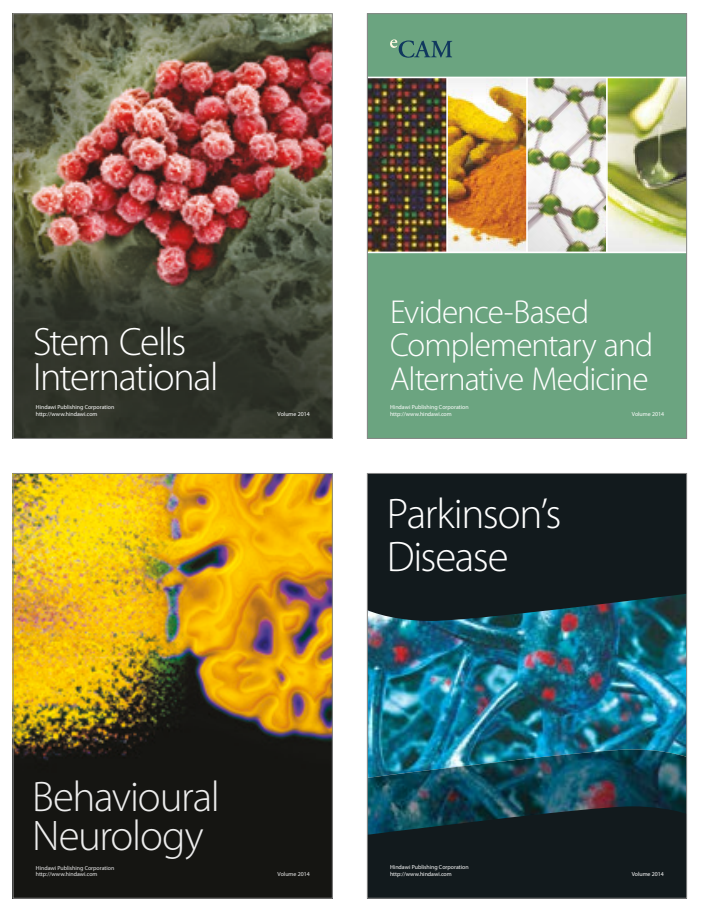
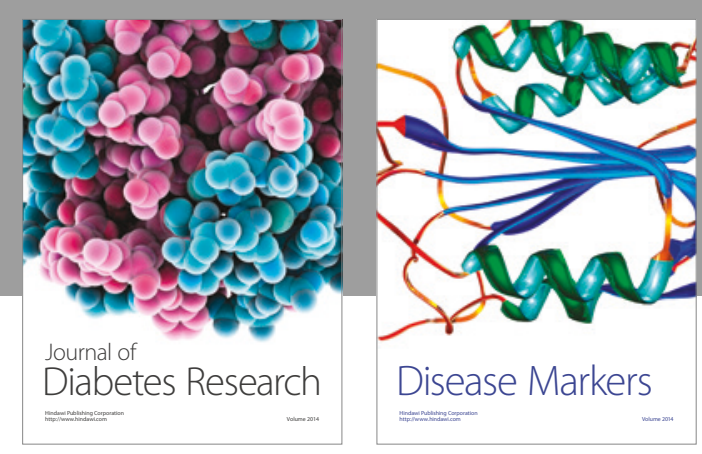

Disease Markers
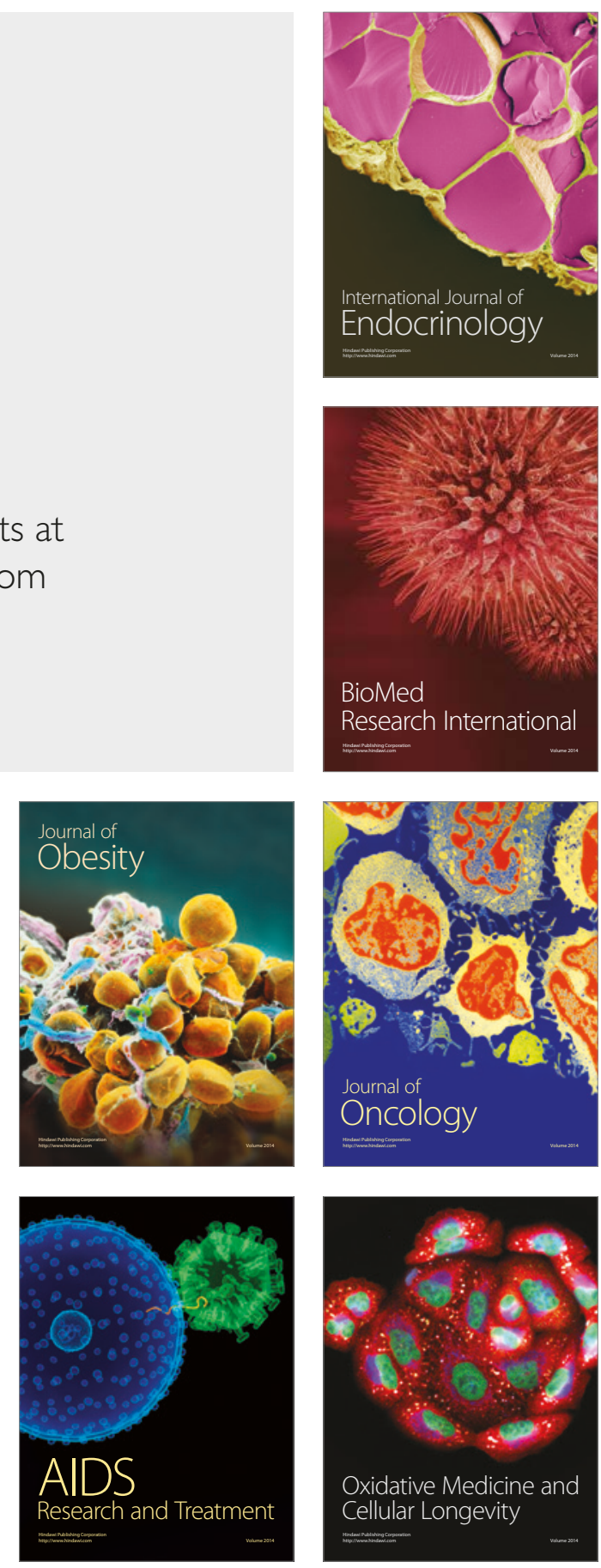